\title{
LA MIRADA DE MEDUSA. ARTE, GÉNERO Y PODER EN EL ECUADOR DE LOS AÑOS 90
}

\author{
MEDUSA'S GAZE. ART, \\ GENDER AND POWER IN \\ 90'S ECUADOR \\ CHRISTIAN LEÓN MANTILLA
}

${ }^{1}$ Universidad Andina Simón Bolívar.

\begin{abstract}
Resumen
Durante la década del 90 del siglo XX se produce un abrupto cambio en el campo del arte en Ecuador que permitió la incorporación de las mujeres en todas las esferas de la producción, circulación, legitimización y puesta en valor del arte. En el contexto del tránsito del modernismo y la contemporaneidad, se caracteriza este momento por la emergencia de nuevas subjetividades y lenguajes en la escena del arte contemporáneo. De un lado, surge el artista como un sujeto plural y sexuado, lo cual es patente en la presencia de nuevos lugares de enunciación construidos por mujeres y minorías sexuales que desafían la cultura patriarcal que había primado en la pintura y la escultura modernista. Del otro
\end{abstract}


lado, se produce una pluralización de los lenguajes a partir de la introducción de la instalación, el assemblage, el performance, la fotografía, el vídeo y la intervención urbana que nutren las estrategias del arte contemporáneo para trabajar la diferencia sexual. El texto plantea la necesidad de retomar las perspectivas sexo-genéricas y las teorías feministas para releer las prácticas artísticas femeninas que desde otros paradigmas terminan invisibilizados. De ahí que recurre a figuras como las de "Medusa" (Cixous) o nociones como las de "mirada matricial" (Pollock) o "misterismo" (Irigaray) que tienen la capacidad de reabrir el campo de significación de la diferencia sexual en el arte contemporáneo y revelan el poder de cuestionamiento que el arte de mujeres tiene hasta la actualidad. A partir de estos enfoques, se reconoce el poder cuestionador que tuvieron las prácticas contemporáneas realizadas por artistas mujeres para cuestionar los valores patriarcales presentes en la pintura moderna y la sociedad ecuatoriana.

Palabras clave: arte, contemporaneidad, género, feminismo, Ecuador.

\section{Abstract}

During the 90 s of the twentieth century there was an abrupt change in the field of art in Ecuador that allowed an incorporation of women in all spheres of production, circulation, legitimization 
and enhancement of art. In the context of the transit of modernism and contemporaneity, this moment is characterized by the emergence of new subjectivities and languages in the emergent context of the contemporary art scene. On the one hand, the artist emerges as a plural and sexed subject, which is evident in the presence of new places of enunciation constructed by women and sexual minorities that challenge the patriarchal culture that had prevailed in modernist painting and sculpture. On the other hand, there is a pluralization of languages from the introduction of installation, assemblage, performance, photography, video and urban intervention that nourish the strategies of contemporary art to work on sexual difference. The text raises the need to revisit the sex-generic perspectives and feminist theories to re-read the feminine artistic practices that from other paradigms end up invisible. That is why he resorts to figures such as "Medusa" (Cixous) or notions such as "matrix gaze" (Pollock) or "misterismo" (Irigaray) that have the ability to reopen the field of meaning of sexual difference in the contemporary art and reveal the power of questioning that women's art has to date. Based on these approaches, he recognizes the questioning power of contemporary practices carried out by women artists to question the patriarchal values present in modern painting and Ecuadorian society.

Keywords: art, contemporaneity, gender, feminism, Ecuador. 
RECEPCIÓN: 1 DE MARZO DE 2018

ACEPTACIÓN: 28 DE JUNIO DE 2018

\section{LA MIRADA}

FEMENINA

Según la mitología griega, la joven Medusa tiene una relación sexual con Poseidón, Dios del mar, este hecho desata la ira de la diosa Atenea, quien maldice y castiga a Medusa transformando sus cabellos en serpientes. Desde entonces, Medusa deviene en un monstruo capaz de convertir en piedra a quien la mire (García Gual, 2003, p. 235). A lo largo de la historia este mito ha generado múltiples interpretaciones que asocian la feminidad a una figura monstruosa que debe ser destruida por el héroe masculino. Recientemente algunas pensadoras contemporáneas han planteado que Medusa representaba el poder y la sabiduría femenina que reinaban antes de la instauración del patriarcado. Ha sido la interpretación masculina predominante, la que ha signado el reinado de lo femenino como una experiencia de horror y monstruosidad. Para Heléenle Cixous, las mujeres han sido inmovilizadas por el mito de Medusa que hace de ellas una metáfora del abismo y la muerte. Frente a esta lectura falocéntrica es necesario confrontar el mito y recuperar la capacidad de creación femenina a través de la escritura, la voz y el cuerpo (1995, p. 54).

El mito de Medusa alude a la violencia como forma de controlar el poder de las mujeres, conjuga la belleza y el horror 
que representa la mujer para la conciencia masculina, es una metáfora que habla del empoderamiento femenino y el miedo que este causa en el varón. Expresa la violencia y el sometimiento, al mismo tiempo la creatividad y el poder femenino. La mirada de Medusa delata la presencia de una subjetividad otra, festiva y poderosa, capaz de horrorizar y desarmar al mundo masculino. "Medusa representa la mujer libre, la mujer no sometida, la mujer pre-patriarcal" (Hernández, 2012, p. 14).

Cuando trato de pensar las metáforas para referirme al arte de mujeres realizado en Ecuador en los años 90, inmediatamente viene a mi cabeza la figura de Medusa. La historia del arte ecuatoriano fundamentalmente estuvo narrada por críticos, historiadores hombres que construyeron un relato que visibilizó el genio masculino e invisibilizó los procesos creativos femeninos. Recordemos que como nos los enseñó Grisela Pollock, la creación artística tradicionalmente estuvo reservada al genio masculino y la historia convencional del arte no fue sino el relato patriarcal de los grandes maestros y sus detractores vanguardistas (2013, p. 118).

Esta forma de concebir la creación y la historia del arte invisibilizó el trabajo de las mujeres artistas y dejó sin relato a las prácticas realizadas desde la diferencia sexual. El relato patriarcal fue sin duda predominante en el arte ecuatoriano desde la colonia hasta finales del siglo xx, solo en los noventa tuvo una inflexión, no libre de contradicciones y denegacio- 
nes. De ahí que a lo largo del siglo xx conocemos poco sobre la obra de artistas como Alba Calderón de Gil, Araceli Gilbert o Germania Paz y Miño de Breilh, aun cuando tuvieron una prolífica obra (Cano, 2014, p. 11). Estas mujeres tuvieron una visibilidad condicionada en el campo del arte, estuvieron siempre en un segundo plano, opacadas por la figura pública de intelectuales y artistas que a su vez eran sus esposos. Como lo advirtió tempranamente Linda Nochlin, al preguntarse "¿Por qué no existen grandes mujeres artistas?, existen condicionamientos históricos, sociales e institucionales que han impedido que las mujeres puedan acceder al estatus de grandes creadoras" (Nochlin, 2008, p. 289).

En Ecuador, a partir de los años noventa, esta situación cambió drásticamente con la presencia de un conjunto de artistas mujeres que devolvieron la mirada al sujeto masculino deconstruyendo los mitos patriarcales. Una pléyade de artistas que hacen pintura, grabado, escultura, instalación, fotografía y vídeo desde una perspectiva contemporánea con el modernismo y abordan abiertamente aspectos de género y sexualidad femenina. Al realizar estos abordajes artísticos de forma autónoma encarnan la mirada de Medusa, aquella perspectiva que aterroriza y petrifica al régimen patriarcal para abrir un nuevo universo sensible que permanecía irrepresentado en el arte ecuatoriano. El conjunto de obras y artistas que emergen en los años noventa hablan de un nuevo empoderamiento de la mujer en el campo de la cultura, remueven los mitos del orden falocéntrico 
en el arte y generan nuevas aporías en donde lo femenino ha dejado de ser el dócil, imaginario hecho a la medida del deseo masculino.

\section{ARTE Y DIFERENCIA SEXUAL EN LOS}

AÑOS 90

La década de los 90 es una época de cambio y transformación en el campo de la economía, la política y la cultura, es un momento de transición e incertidumbre ya que el orden establecido del Ecuador moderno se cierra para dar paso a la contemporaneidad. De ahí que esta década pueda ser considerada como una bisagra entre el nacionalismo y la globalización, el estatismo y el neoliberalismo, la modernidad y la contemporaneidad. Los años 90 constituyen el colofón de una serie de procesos del siglo xx que anuncian las transformaciones y cambios que se vislumbrarán con claridad en el nuevo siglo. Cómo lo apuntan Kingman y Cevallos, la década está marcada por cinco grandes cambios: 1) el neoliberalismo 2) la crisis económica 3) la caída del Muro de Berlín 4) la emergencia de nuevos movimientos sociales y 5) la ausencia de políticas y crisis de las instituciones culturales (2016).

En este contexto de transformación e incertidumbre, se produjo una grave crisis en el campo del arte que finalmente desembocó a mediados de la década en la emergencia de nuevos actores y prácticas. Los años 90 representan en el campo del 
arte un saludable relevo generacional que va a permitir el tránsito del modernismo a la contemporaneidad que dialoga con la consolidación del arte contemporáneo que se está produciendo en América Latina. En este momento, se plantea la crisis del campo artístico hegemonizado, hasta ese entonces, por los pintores indigenistas, neofigurativos y expresionistas que se beneficiaron del boom petrolero y un mercado del arte inflacionario. Es en ese contexto que surge un conjunto de prácticas que Lupe Álvarez denominó como "arte nuevo", la novedad de estas prácticas artísticas de mediados de los 90 está relacionada con "una visión estratégica instruida del acto creativo" de alta capacidad de inserción en el contexto que es capaz de criticar las retóricas esencialistas para hacer un comentario mordaz sobre la realidad (Álvarez, 2001, p. 411). Sin embargo, la noción de arte nuevo planteado por Álvarez dejaba intacto uno de los esencialismos más arraigados del modernismo ecuatoriano, el del genio creador masculino y, al mismo tiempo dejaba sin relato a un conjunto de prácticas artísticas que encaraban de forma crítica las disputas de género.

\section{LA ARTISTA COMO SUJETO SEXUADO}

En los años noventa, el assemblage, la instalación, el performance, la fotografía y el vídeo se transformaron en recursos fundamentales que permitieron cuestionar la hegemonía de la pintura y la escultura, de la misma manera, impulsaron un dialogo con los lenguajes contemporáneos del 
arte latinoamericano, norteamericano y europeo. Al mismo tiempo estas técnicas fueron usadas como una herramienta capaz de registrar las complejas posiciones del deseo, el cuerpo y la sexualidad inscrita en marcos políticos, culturales y sociales. Estas herramientas se convierten en un finísimo pincel capaz de expresar una serie de dimensiones sociales y subjetivas, que adquiere el cuerpo sexuado en oposición a la figura trascendental del genio creador, que como sabemos, siempre es masculina y heteroposicionada. De igual modo, mencionamos a artistas que han trabajado temas relacionados con la feminidad, como Jenny Jaramillo, Ana Fernández, Larissa Marangoni, Diana Valarezo, Judith Gutiérrez, María Pérez, Pamela Hurtado, Clara Hidalgo, María Salazar, Sara Roitman. Junto a ellas cabe destacar a artistas que han abordado el tema de diversidades sexuales como Santiago Reyes, Marco Alvarado, Óscar Villegas, Sara Roitman y Verónica León.

De forma lenta y silenciosa, la introducción de prácticas contemporáneas en el campo artístico ecuatoriano, permitió la ampliación de fronteras y el cuestionamiento de los límites de la representación artística. Como sucede en otros contextos, el arte contemporáneo ha sido un escenario para la crítica de la opresión y la marginación contra las mujeres, la afirmación política de lo personal, la reflexión sobre la historia cultural de las mujeres, y la introducción del propio cuerpo sexuado del artista como materia significante, y disparador político de la práctica artística (Reckitt y Phelan, 2005). 
Desde nuestro punto de vista la nueva relación entre arte y género que se rearticula en los años noventa tiene cinco rasgos que la caracterizan: a) feminización del campo artístico. b) introducción en el campo artístico de cuerpo sexuado c) el uso de lenguajes y estrategias contemporáneas d) deslegitimación de posturas militantes e) paralelismo con los movimientos sociales basados en derechos sexuales.

\section{A) FEMINIZACIÓN DEL CAMPO}

\section{ARTÍSTICO}

La década del noventa es un momento de eclosión de

la expresión femenina en el campo de las artes. Como en ningún otro momento de entonces se configura en cantidad y calidad, una presencia femenina en todas las instancias de producción de valor del fenómeno artístico. En una reciente investigación, sobre el rol de las mujeres en la escena del arte contemporáneo en Ecuador, Arianni Batista sostiene: "A partir de la década del noventa se produce un agenciamiento femenino de varios de los espacios del circuito de producción y circulación de las artes visuales, tradicionalmente reservados a los hombres" (2013, p. 12). Por un lado, tenemos la emergencia de una generación de artistas mujeres que entran a disputar y pluralizar un escenario que anteriormente había sido tradicionalmente masculino. Por otro lado, se produce una inédita feminización de la gestión cultural en el campo del arte, 
como había sucedido en otras áreas como lo ha planteado Paola de la Vega (2016, p. 137).

Para Batista este nuevo agenciamiento femenino en el circuito de producción artístico es patente en el incremento de mujeres en las carreras de artes, especialmente en la Universidad Central donde por primera vez existen más mujeres que hombres; en el incremento de mujeres que exponen en galerías como La Galería y Madeleine Hollaender, al igual que en el aumento de reseñas y notas críticas sobre artistas mujeres en revistas como Diners y El Buho. Es en este contexto que aparecen artistas mujeres que empiezan a trabajar temáticas de género y sexualidad en clave contemporánea, como se apunto anteriormente. Del lado de los circuitos de circulación y puesta en valor, destaca la presencia de importantes galeristas como Betty Wappenstein, Madeleine Hollaender y Marcela García; así como un conjunto de críticas e historiadoras que legitimaron las prácticas contemporáneas: Lupe Álvarez, Alexandra Kennedy, Trinidad Pérez, Mónica Berbecí, Inés Flores, Milagros Aguirre, María Fernanda Cartagena y María del Carmen Carrión.

Al reflexionar sobre las posibilidades de transformación de las mujeres a través de los dispositivos visuales, Annette Kuhn sostuvo que "El texto no es sino un elemento más de una serie de relaciones sociales de producción cultural" (1991, p. 28). Siguiendo esta idea de Kuhn podemos entender a la década del noventa como un umbral en el cual el discurso artís- 
tico se transforma radicalmente como efecto de profundos cambios en la estructuras de producción cultural y social, generando una nueva forma de distribución y significación de aspectos relacionados con el género y la sexualidad. En este sentido, los años noventa marcan una profunda reconfiguración, silenciosa e invisible, de los discursos y las estructuras culturales que permiten una nueva relación entre arte y género en el contexto de la disputa entre modernidad y contemporaneidad.

\section{B) EL CUERPO SEXUADO EN EL}

\section{CAMPO ARTÍSTICO}

Una de las características del arte realizado por mujeres en los años 90, es la prerrogativa de dar cuenta de la experiencia vivida más allá de las formas de objetivación del cuerpo femenino, las cuales prevalecieron a lo largo de la historia del arte ecuatoriano. Frente a las imágenes construidas desde la mirada masculina que subordinaban a las mujeres al rol sumiso de objetos del deseo, musas y mujeres fatales, las artistas de los años 90 reivindicaron una subjetividad autónoma. De la mirada patriarcal prodominante en la pintura indigenista, neofigurativa y expresionista pasamos a lo que Griselda Pollock denomino como "mirada matrizial". Este tipo de mirada nos remite a un conjunto de fantasias relacionadas con el misterio del cuerpo materno en donde aún no han operado las separaciones entre sujeto/objeto, mente/cuerpo, cul- 
tura/naturaleza, la mirada/lo mirado, propias del falocentrismo (Pollock, 2000, p. 337). Como ninguna otra época en la historia del arte ecuatoriano surgen un repertorio de imaginarios y discursos que exploran, cuestionan y deconstruyen los lugares comunes y los estereotipos con los que tradicionalmente representó a las mujeres como cuerpo, objeto y natuleza dispuesta para la mirada masculina.

Esta crítica se va a dar por dos caminos: de un lado, a través de la incorporación de la experiencia personal encarnada en el cuerpo, del otro lado, a través de la reivindicación de una serie de características subalternas con las cuales se signó a la mujer. A través de una serie de complejas estrategias artísticas se alude a la experiencia biográfica del cuerpo sexuado que oscila entre la identificación con vivencias propiamente femeninas y el rechazo a las formas de violencia patriarcal. Dentro de las luchas de las artistas mujeres, el trabajo sobre su propio cuerpo constituyó una forma de "socavar las connotaciones de pasividad y contemplación de la desnudez femenina" (Heartney, 2008, p. 218).

Las experiencias subjetivas y las significaciones socio-culturales vividas a través del cuerpo se transforman en un tema central, a tomo con la consigna feminista de que lo personal es político. Parafreseando a Barbara Kruger, en una de sus emblemáticas obras de finales de los 80 , el cuerpo se convirtió en un campo de batalla. Los cuadros informalistas así como los videoperformance de Jenny Jaramillo trabajan en la 
deconstrucción y la indecibilidad del cuerpo sexuado como una política de la diferencia. La elaboración de ficciones autobiográficas realizada por Larrisas Marangoni y María Pérez pueden ser interpretadas en esta dirección. Esta introducción del cuerpo sexuado en el arte de los años 90 va a ser la semilla para un conjunto de prácticas contemporáneas posteriores que tematizan aspectos sociales y culturales relacionados a construcciones de clase, género, étnicas y sexuales. El arte de mujeres de los años 90 es el antecedente del trabajo que en los 2000 realizarán artistas como Valeria Andrade, Karina Aguilera, Saskia Calderón, Janeth Méndez, entre otras.

Paralelamente se plantea una reivindicación de espacios y valores, tradicionalmente concebidos como inferiores, los cuales estaban relacionados a la mujer. Como lo ha planteado Rosa Olivares: "La esencia de la mujer no radica exclusivamente en el egocentrismo sexual, sino en la versión de lo extremo, de la periferia" (1998, p. 39). En esta dirección muchas artistas revindican el valor de lo decorativo, lo artesanal, lo popular, lo doméstico y lo personal como fuente de una nueva estética asociada a la feminidad. En este sentido se puede entender el trabajo con referentes de la cultura popular realizado por Jenny Jaramillo y Ana Fernández, de igual manera el trabajo con objetos domésticos y juguetes realizados por Pamela Hurtado. La apropiación crítica de actividades femeninas como la costura, el tejido, la cocina y la elaboración de objetos decorativos es una estrategia de reivindicación de las prácticas 
tradicionalmente subalternas. Esta tradición va a ser continuado en el nuevo siglo por artistas como Magdalena Pino, María José Icaza, Gabriela Chérrez, Pamela Pazmiño, entre otras.

\section{C) LENGUAJES Y ESTRATEGIAS}

\section{CONTEMPORÁNEAS}

Los caminos para esta apertura a las perspectivas sexogenéricas van a venir de la cantera del conceptualismo, el apropiacionismo, la crítica institucional, pero también del arte corporal, el performance y el videoarte que confluyen en la escena contemporánea. En un intento de aproximación a los lenguajes de las prácticas realizadas por las mujeres en los años 90, proponemos cuatro tipos de líneas de trabajo: aproximaciones críticas a la pintura, la escultura expandida y el arte de objetos, así como las prácticas corporales.

En el primer caso tenemos un conjunto de artistas que se ubican en el umbral entre el modernismo y la contemporaneidad que trabajan críticamente con los lenguajes de la pintura, el grabado y el dibujo. Artistas como Pilar Bustos, Diana Valarezo, María Pérez, Claridad Hidalgo, María Salazar realizaron una visibilización del erotismo y las simbologías femeninas que de forma sutil hace un comentario al androcentrismo de la pintura moderna. En la segunda línea nos encontramos con artistas como Larissa Marangoni, Consuelo Crespo y Lorena Espinosa que hacen un uso contemporáneo de la escultura para cuestionar los roles que género y las formas de subjeti- 
vidad femeninas. Por otro lado, destacan artistas que trabajan críticamente con los lenguajes del assemblage, el objeto encontrado y la instalación para deconstruir el sistema de los objetos relacionados al universo femenino. La pionera en esta exploración es Pamela Hurtado, pero junto a ella podemos citar las obras tempranas de Ana Fernández, los objetos e instalaciones de finales de los noventa de Juana Córdova, así como las esculturas orgánicas posminimalistas de Janeth Méndez.

En una tercera línea se ubican obras que trabajan de forma directa o alegórica con el cuerpo, aquí toma protagonismo el performace o arte de acciones. El performance ofrece a las mujeres la posibilidad de crear nuevos significados ya que no tiene una tradición abrumadora, técnicas establecidas y sentidos asignados. De ahí que ha permitido "reformulaciones de identidades inventivas, estimuladas por visiones antiasmáticas y demandas políticas en torno al género y la sexualidad" (Jones y Warr, 2006, p. 13). En esta dirección destaca el arte de acciones de Jenny Jaramillo, que contrapone gestos y significantes femeninos de forma opositiva y desconcertante, y Ana Fernández, quien en los últimos años crea su personaje Miranda Texidor, un álter ego performático de su condición femenina.

Las artistas mujeres a través del trabajo crítico con la imagen bidimensional, la escultura, los objetos y el propio cuerpo, deconstruyen las certezas del discurso patriarcal en el campo social y en el campo artístico. Por medio de estos nuevos len- 
guajes y estrategias, las artistas aluden a esa instancia de la realidad que Luce Irigaray denomina como "mistérica" (Irigaray, 2007, p. 175). Según Irigaray la acción mistérica nos invitan traspasar la pantalla de las representaciones masculinas para zambullirnos en el mundo subterráneo, misterioso y místico cobijado por la oscuridad de la noche que no alcanza a ser dominado por el ojo patriarcal.

\section{D) DESLEGITIMACIÓN DE POSTURAS} MILITANTES

En la caracterización de las nuevas prácticas artísticas de los años noventa que hace Lupe Álvarez, plantea que hay una vuelta a la función social del arte a través de comentarios críticos, sobre la realidad, el contexto y los problemas económicos, políticos y sociales que atravesaba el país. Según la curadora cubana, la actitud de los artistas de la época está marcada por el escepticismo y la distancia en oposición a la ética del compromiso y la militancia que caracterizó a las generaciones pasadas (Álvarez, 2001, p. 412).

Esta forma de interpretar la función social del arte parece estar presente en los debates sobre problemáticas sexo-genéricas. Muchas artistas viven la violencia de género, ya que afrontan cotidianamente la desigualdad de oportunidades en el espacio público, el trabajo, el hogar y la familia, sufren y luchan contra las jerarquías patriarcales. De alguna manera son feministas sin saberlo y sin etiquetas. De formas muy di- 
versas el feminismo ha estado presente en la práctica de las artistas y en la historia del arte, "El feminismo ha redefinido los términos esenciales del arte de finales del siglo $x x$, poniendo de relieve presunciones culturales sobre el género, y politizando el vínculo entre lo público y lo privado, explorando la naturaleza de la diferencia sexual y realzando la especificidad de los cuerpos determinada por el género, la raza, la edad y la clase social" (Reckitt y Phelan, 2005, p. 13).

En los noventa nos encontramos con un conjunto de obras que aluden y cuestionan a través de la ironía, el sarcasmo, la paráfrasis, el pastiche a la violencia y la subordinación de género, sin embargo, rechazan las posturas militantes, cuestionan las narrativas de denuncia y, en algunos casos, miran el feminismo con distancia. En un diagnóstico de la relación arte y género realizado a mediados de los noventa, Trinidad Pérez sostenía que el feminismo era percibido como algo del pasado (Batista, 2013, p. 23). Las posturas militantes y las narrativas de denuncia eran vistas como una herencia del realismo social del cual había que alejarse. El campo del activismo político era considerado como el lugar de perdida de la individualidad y formas de expresión poco innovadoras. Esta postura latente en la obra de algunos artistas y legitimada por la crítica de la época, volvió antitéticos la esfera del arte contemporáneo y el mundo del activismo por causas sociales, al mismo tiempo, deslegitimó la posición de artistas que adscribían al feminismo y sus luchas. 
Sin embargo, la postura de las artistas que trabajaban temas de género y sexualidad respecto del feminismo es tan variada como compleja. Jenny Jaramillo tenía una postura distante frente a las luchas y teorías feministas, para la artista la fuente de su trabajo constituía primordialmente la experiencia vivida como mujer. Según Jaramillo, en su generación existió un desconocimiento de la teoría feminista lo cual impidió que las artistas que trabajaban temas de género se reconocieran entre sí. "Las artistas mujeres desconocíamos los aportes de la teoría feminista, eso de alguna manera no permitió crear diálogos entre temáticas" (Jaramillo, 2016, p. 4).

Artistas como Larissa Marañona y Ana Fernández habían cruzado sus estudios en New York y en San Francisco respectivamente, ciudades con una fuerte tradición de activismo y pensamiento feminista. Este hecho hizo que ambas reconocieran tempranamente al feminismo como una brújula de sus procesos creativos. En una entrevista que le hicimos para la redacción de este texto, Fernández reconoció su lucha permanente contra el sexismo, dijo: "hace muchos años me considero una feminista muy fuerte" (Fernández, 2016, p. 1). Por su parte, Marangoni, quien también se define abiertamente como feminista sostiene que "esa es la valentía del feminismo, de poder hablar y expresarse abiertamente las sensaciones" (Batista, 2013, p. 172). Ambas artistas, aunque se consideran feministas, creen que las formas de expresión del arte son distintas de las formas de expresión políticas y reivindican la 
especificidad de los lenguajes artísticos. En el caso de Jaramillo, Fernández y Marangoni es patente un esfuerzo por incorporar aspectos de la cultura local y ponerlos en diálogo con los aportes de la tradición crítica del arte feminista internacional. En su performance Desasentar (2004), Jaramillo realiza un conjunto de acciones encarnando el cuerpo de una mujer indígena. En la serie pictórica Que el soberbio Pichincha decora (2000), Fernández retoma el lenguaje de la gráfica popular y la pintura naif para trabajar una serie de representaciones paródicas sobre la nación y sus héroes masculinos. En su escultura No soy tu adorno (2004), Marangoni presentaba una gran lámpara artesanal barroca en la cual lo decorativo se transformaba en algo siniestro.

\section{E) PARALELISMO CON LOS}

\section{MOVIMIENTOS SOCIALES}

En los años 90, el movimiento de mujeres se reorganiza en torno a la lucha contra la violencia de género, la defensa de los derechos sexuales y reproductivos, la equidad en la participación política y el reconocimiento del trabajo doméstico como productivo, mientras que colectivos gais exigen el reconocimiento de derechos para las diversidades sexuales (Goetschel et al., 2007, p. 37). Estas luchas van a plasmarse en la construcción de una nueva cultura ciudadana respecto del género y la sexualidad y en la aprobación de distintos marcos legales como la Ley contra la Violencia 
de la Mujer y la Familia (1995), la despenalización de la homosexualidad plasmada en el Código Penal (1998) y el reconocimiento de equidad de género en la vida política y ciudadana así como la ampliación de derechos para las diversidades sexuales conseguidos en la Constitución de la República (1998). Paralelamente a estas luchas de reivindicación sexo-genérica, surge una generación de artistas que a través del uso de distintos medios están posicionando discusiones sobre la epistemología del cuerpo, sus usos sociales, sus implicaciones respecto de la orientación del deseo, sus relaciones con los roles de género y su articulación con las políticas sexuales.

A pesar de esta sincronía de sucesos que ocurrían en los movimientos sociales y en la práctica de los artistas, el diálogo ante la esfera artística y el campo del activismo ha sido casi inexistente. Son esporádicos los casos de colaboración de artistas con instituciones como el Consejo Ecuatoriano para la Promoción y Acción de la Mujer (CEPAM) o la Asociación Femenina de Trabajadoras Autónomas (AFTA). Un caso relevante para mencionar es Diana Valarezo, quien en 1989 ganó el primer premio del concurso de afiches sobre la Violencia contra la Mujer. Esta ausencia de diálogo entre el arte y el campo el activismo en gran parte puede ser explicado por valores tradicionales del campo artístico que abrazaron la autonomía como un valor a ser defendido y una incomprensión de el poder subversivo del arte dentro de los movimientos políticos de los años 90. 
Solo hace unos pocos años ha empezado un saludable intercambio que conjuntamente han producido proyectos que han puesto en diálogo a organizaciones feminista, GLBTI y artistas contemporáneos. Organizaciones como: Taller de Comunicación Mujer, Casa Feminista de Rosa, El Proyecto Transgénero, Articulación Esporádica, Fundación Causana y Silueta $X$ han encontrado en el trabajo artístico un aliado para sus luchas.

\section{CONCLUSIONES}

Recapitulando, podemos decir a ciencia cierta que durante los años noventa existió un cambio en el campo del arte y la cultura ecuatoriana que permitió una incorporación inédita de las mujeres en todas las esferas de la producción; circulación, legitimización y puesta en valor del arte. En el contexto del tránsito del modernismo y la contemporaneidad, se produce una saludable feminización en la creación, producción y gestión de las artes. De ahí que se pueda entender la década de los noventa como un momento de emergencia de nuevas subjetividades y nuevos lenguajes, en el contexto de la aparición de la escena del arte contemporáneo. De un lado, surge el artista como un sujeto plural y sexuado, lo cual es patente en la presencia de nuevos lugares de enunciación construidos por mujeres y minorías sexuales que desafían la cultura patriarcal que había primado en la pintura y la escultura modernista. Del otro lado, se produce una pluralización 
de los lenguajes a partir de la introducción de la instalación, el assemblage, el performance, la fotografía, el video y la intervención urbana que nutren las estrategias del arte contemporáneo para trabajar la diferencia sexual.

En este contexto, las perspectivas sexo-genéricas van ganando terreno en el arte contemporáneo a través de la crítica de la mirada patriarcal de la pintura indigenista, neofigurativa y expresionista. Esta apertura se da de espaldas al discurso legitimador del arte contemporáneo que se centró en la crítica de lo social y el rechazo a las posturas militantes por considerarlas modernistas y obsoletas. A pesar de estas omisiones, hay suficientes evidencias para advertir la presencia de una contundente productividad de las perspectivas sexo-genéricas en el arte de los noventa que alcanza legibilidad a través de la crítica feminista. De ahí que nos parezca que nociones figuras como las de Medusa (Cixous) o nociones como las de mirada matricial (Pollock) o misterismo (Irigaray) reabren el campo de significación de la diferencia sexual en el arte contemporáneo de los años noventa y revelan el poder de cuestionamiento que el arte de mujeres tiene hasta la actualidad. En palabras de Hélène Cixous "Para ver a la Medusa de frente basta con mirarla: y no es mortal. Es hermosa y ríe" (1995, p. 21). 


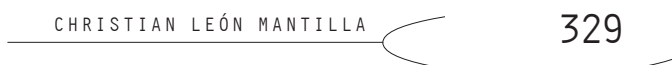

\section{Bibliografía}

Álvarez, G. (2001). Antigüedades recientes en el arte ecuatoriano. En Políticas de la diferencia. Arte iberoamericano de fin de siglo. Valencia: Generalitat Valenciana

BATISTA, A. (2013). El arte contemporáneo en el Ecuador. La producción femenina en la configuración de la escena (1990-2012) (Tesis de la Maestría en Antropología Visual y Documental Antropológico ed.). Quito: FLACSO.

CANO, M. H. (2014). Araceli Gilbert: la mirada desde una perspectiva feminista a su producción artística. Quinto: Universidad San Francisco de Quito. Colegio de Ciencias y Humanidades.

Cixous, H. (1995). La risa de Medusa. Ensayos sobre la escritura. Barcelona: Anthropos.

De LA VegA, P. (2016). Gestión Cinematografica en Ecuador: 1977-2006. Quito: Gescultura,

Fernández, A. (diciembre de 2016). Entrevista. Proyecto de investigación "Género y sexualidad en el arte ecuatoriano en la década del 90". (C. León, Entrevistador)

García Gual, C. (2003). Diccionario de mitos. Madrid: Siglo XXI.

Goetschel, A. M., Pequeño, A., Prieto, M. y Herrera, G. (2007). De memorias. Imágenes públicas de las mujeres ecuatorianas en comienzos y fines del siglo veinte. Quito: FONSAL y FLACSO.

Heartney, E. (2008). Arte \& Hoy. London: Phaidon.

Hernández, N. B. (2012). Mirar a madusa. Una invitación a atravesar la petrificación y deshacer y desacernos de su maldición. Barcelona: 
Universidad de Barcelona/Máster en Estudios de la Libertad Femenina.

Irigaray, L. (2007). Espéculo de la otra mujer. Madrid: Akal.

JaRAmillo, J. (diciembre de 2016). Entrevista. Proyecto de investigación "Género y sexualidad en el arte ecuatoriano en la década del 90". (C. León, Entrevistador)

Jones, A. Y WARR, T. (2006). El cuerpo del artista. Londres: Phaidon.

Kingman, M. y CeVallos, P. (2016). Arte, modernidad y contemporaneidad en el Ecuador de los noventa. Quito: Pontificia Universidad Católica del Ecuador, Carrera de Artes.

Kunn, A. (1991). Cine de mujeres. Feminismo y cine. Madrid: Cátedra.

NoCHLIN, L. (2008). ¿Por qué no ha habido grandes mujeres artistas? En Amazonas del arte nuevo, catálogo de la exposición (pp. 283-289). Madrid: Fundación Mapfre.

Olivares, R. (1998). Mujeres, al fin. Lápiz. Revista internacional de arte, 38-49.

Pollock, G. (2000). Inscripciones en lo femenino. En A. M. Guasch, Los manifiestos del arte posmoderno. Textos de exposiciones 1980-1995 (pp. 322-346). Madrid: Akal.

_ (2013). Visión y diferencia. Feminismo feminidad e historias del arte. Buenos Aires: Fiordo.

ReCKITT, H. y PhelAN, P. (2005). Arte y feminismo. Londres: Phaidon. 